\title{
La imagen del guerrero en el mural "La fusión de dos culturas" de Jorge González Camarena
}

The warrior's picture in the mural "La fusión de dos culturas" from Jorge González

LUIS MIGUEL REBOLLAR VERGARA*

México

*I_mike87@hotmail.com

iD https://orcid.org/0000-0001-6388-8973

Artículo de investigación Recepción: 15 de Octubre de 2019 Aprobación 06 de Marzo de 2020

Cómo citar este artículo:

Rebollar, L. (2019). La imagen del guerrero en el mural "La fusión de dos culturas" de Jorge Gonzáles Camarena Designio. Investigación en diseño gráfico y estudios de la imagen 1(2), pp. 52-66

Recuperado a partir de: http://cipres.sanmateo.edu.co/index.php/designio 
Resumen: El objetivo del presente artículo es realizar un análisis iconográfico e iconológico sobre la obra pictórica "La fusión de dos culturas" del muralista Jorge González Camarena. La finalidad es demostrar si la vestimenta de los guerreros presentes en la obra antes mencionada, corresponde al atavío. Lo anterior, con base en las fuentes arqueológicas que dan un acercamiento más preciso; también contextualiza, más a fondo, dónde se sitúan las representaciones pictóricas. Además, ofrece una respuesta a si estas son certeras según las fuentes arqueológicas y no solamente a lo que refieren las fuentes históricas.

Palabras clave: Camarena; mural; imagen; guerrero águila; caballero español; atavío y armamento.

Abstract: The objective of article is to carry out one analysis iconographic - iconologic of the work "the fusion of two cultures" of painter Jorge González Camarena. The intetion is to prove if the attire of the warriors in the paint to correspond to the attire original. With base a the sources archaeologics more exactand and to contextualize that representations of the images. The article pretend to give one answer accurate in relacion on the sources archaeologics y ant not only with thah sources historics.

Keywords: Camarena; wall painting; image; eagle warrior; knight español; attire and armament. 


\section{Introducción}

Para realizar un artículo sobre la imagen del guerrero, específicamente del mundo mexica, en la obra "La fusión de dos culturas" del muralista Jorge González Camarena” se debe retomar bibliografía que enriquezca dicho producto final. Así, según el objetivo antes plateado, el artículo se centra en algunos conceptos referidos por los autores Doctor (Dr.) Marco A. Cervera Obregón, Maestra Adriana Macías Mader, Licenciado (Lic.) Miguel Ángel Ibarra Bucio, Antonio Luna Arroyo, Alfredo López Austín y Leonardo López Luján. Esto, para la interpretación de la imagen del guerrero mexica y del caballero español (personajes que ocupan el espacio pictórico y gira la temática de la obra).

Además, como primer punto de partida para la interpretación de la obra, es indispensable retomar fuentes históricas que aborden acontecimientos relevantes del mundo mexica. Para ello, retoma los textos de los autores antes mencionados. Por otro lado el interés particular, para el desarrollo del presente artículo, es demostrar si la vestimenta de los guerreros presentes en la obra“La fusión de dos culturas" corresponde a la vestimenta. Esto con base en las fuentes arqueológicas que ofrecen un acercamiento más preciso de cómo estaban ataviados el guerrero águila y el caballero español.

Por otra parte, la relevancia del presente artículo es demostrar la importancia de la imagen del guerrero dentro de la historia del arte; sólo se da prioridad a los acontecimientos históricos y dejan de lado a los verdaderos protagonistas, en este acaso los guerreros frente en las batallas.

Este es un enfoque dentro de las disciplinas de la historia, a saber, la historia del arte y la arqueología, sin embargo, no son tomadas en cuenta. No obstante, es de suma importancia para el entendimiento a profundidad del contexto en el que se sitúan las representaciones pictóricas y se aclara la certeza de las obras con base en las fuentes arqueológicas y no solamente a lo que refieren las fuentes históricas.

Según la información anterior, la pregunta de investigación para este artículo es ¿Cuáles son los elementos que conforman la vestimenta tanto del guerrero mexica del caballero español con los que se encuentran ataviados? Se pretende dar respuesta al interrogante con el fin de aseverar o desmitificar si los elementos presentados por el artista, en la vestimenta de los personajes presentes en la obra, corresponden a las fuentes antropológicas que ofrecen un acercamiento con mayor veracidad.

Para el análisis del mural Jorge González Camarena, en primera instancia se realiza una investigación a través de la consulta de fuentes históricas (Alfredo López Austín y Leonardo López Luján) y arqueológicas (Dr. Marco A. Cervera Obregón, Maestra 
Adriana Macías Mader, Lic. Miguel Ángel Ibarra Bucio, Antonio Luna Arroyo). Lo anterior sitúa la escena de combate entre los dos (2) personajes, así como los elementos que conforman la vestimenta de los guerreros (en realidad es certera la interpretación que el pintor da al traje del guerreo águila, la armadura del guerrero español y el armamento).

En segunda instancia se produce un análisis iconográfico de la obra. Es decir, qué se percibe en el espacio pictórico, la descripción de lo que se ve a simple vista y la edificación de los elementos presentes como el traje, la armadura y el armamento de los personajes situados en el mural.

Figura 1. La fusión de dos culturas. Jorge González Camarena. 1963. Acrílico sobre tela. Sala 2 del Castillo de Chapultepec, Ciudad de México.

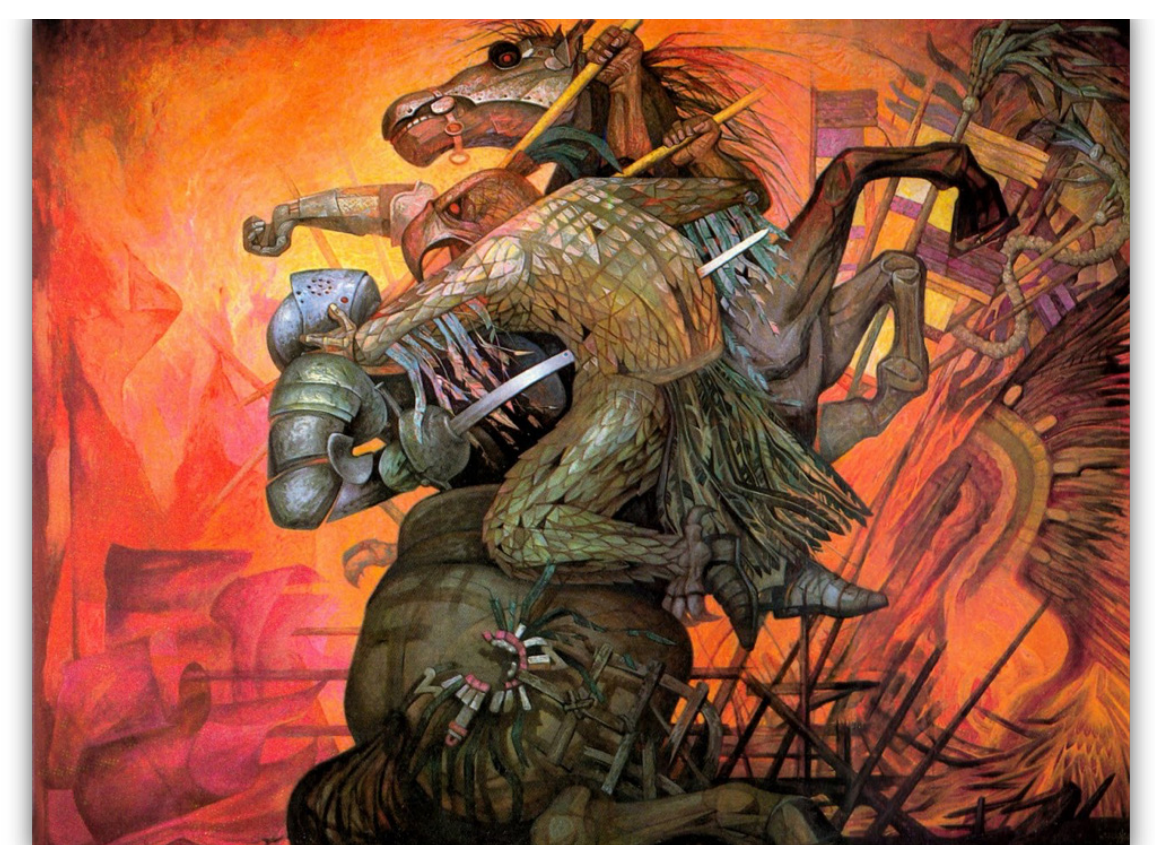

\section{Descripción de la escena}

El conquistador español montado en su caballo, se encuentra frente a un guerrero águila -correspondiente a la cultura mexica-. En la escena de batalla se percibe la conquista militar por parte de los españoles, así como la violencia y la muerte en contra de los mexicas. 


\section{Referencias del Pintor}

\section{Vida y obras de Jorge González Camarena. ${ }^{1}$}

Jorge González Camarena nació en 1908 en Guadalajara, Jalisco. Desde su corta edad, Camarena tuvo una gran inquietud por la pintura; "mientras su hermano Luis salía a jugar, él se quedaba a observar como su tía Esther pintaba" (CONACULTA, 1996). Durante su época se presenta un gran auge en la escuela de pintura. En su generación hubo artistas que explotaron el arte pictórico; en sus creaciones reflejaron temas como el triunfo de la Revolución. Además, estas obras tenían la categoría, y eran vistas, como comerciales.

El pintor incursionó en proyectos publicitarios por la relación que tuvo con suvecino Federico Sánchez Fogarty, quien convirtió sus obras en un arte comercial. Así, Camarena fue contratado por empresas mexicanas para la decoración de edificios, como es el caso de Cementos Tolteca con su mural "Molinos y el indio" o la Casa editorial Galas de México. También pintó iglesias como el exconvento de Huejotzingo en Puebla del siglo XVl; a partir deeste momento el artistase interesóy dio inicio a una carrera prometedora.

En lo relacionado con su estilo, es único, representativo e identificable; se caracteriza en romper con los estilos de los anteriores y reconocidos muralistas. Exalta las figuras con firmeza y realismo, utiliza elementos para su compasión paisajes y estructuras arquitectónicas. También juega con los planos y los relieves creando un efecto escultórico, monumental y cubista, con tanto vigor que resalta su sello personal.

Las obras de Camarena exaltan el humanismo como tema principal; enfatiza la necesidad y la preocupación del bienestar material y espiritual del ser humano. De la mano con lo anterior, muestra la historia de México desde su visión e interpretación de los hechos; este proceso lo conoce el artista como la síntesis del mestizaje. Por último, muestra los orígenes de nuestra nacionalidad.

El pintor, además de contribuir en conocimientos referentes al diseño gráfico, inventó una técnica propia denominada 'el cuadratismo'; consiste en organizar los

\footnotetext{
1 Jorge González Camarena (1908-1980) nace en Guadalajara, Jalisco un 24 de marzo. Su gran producción muralística "La Fusión de dos Culturas" representa el nacimiento de la cultura mexicana como producto del choque de dos culturas distintas: la náhuatl, floreciente en Mesoamérica, y la española. Esto se ve simbolizado en las figuras del guerrero águila y el conquistador español, los cuales mueren al mismo tiempo en la lucha. En el extremo inferior derecho se observa una pequeña águila que surge en medio del fragor de la batalla. Representa el nacimiento de México gestado en el crisol de la guerra de Conquista. Al fondo del mural, tanto a la derecha como a la izquierda, se aprecian las insignias de los dos bandos: los penachos y estandartes indígenas y las banderas españolas, consumiéndose en el fuego de la batalla. (Mexicana Repositorio del Patrimonio Cultural en México, 2017: en red).
} 
objetos dentro de un cuadro con base a la geometría. Para Camarena "el muralismo era la máxima expresión de la pastica en todas sus dimensiones, era la gama de todo el arte de la pintura, la perfección de todo el conjunto de obras de un pintor" (Luna, 1981, p. 37).

\section{Contexto histórico - Los mexicas}

\section{Visión de la cultura mexica.}

Para el entendimiento del tema expresado en la obra objeto de estudio, es relevante mencionar la información correspondiente de la cultura mexica, así como algunos acontecimientos históricos que marcaron a dichos pobladores. Algunas fuentes históricas hacen referencia a un pueblo de guerreros cuando se estudia a la cultura mexica; su dominio y poder abarcó un territorio extenso a su alrededor. Este pueblo se asentó en la Ciudad de México-Tenochtitlán, su desarrollo como población y su dominio se divide en cuatro periodos (López, 2001):

1. Asentamiento de la población en la zona del lago de Texcoco y vida subordinada por el poder de los Tepanecas (1325-1430).

2. Estructuración del estado hegemónico tras la derrota de Azcapotzalco (1469).

3. Expansión militar (1502).

4. Consolidación de los dominios hasta la invasión europea.

\section{Asentamiento de la población mexica.}

Algunas fuentes escritas revelan que el asentamiento de la población mexica surge a partir de la migración desde Aztlán, lugar donde permanecieron. Estos acontecimientos son relevados en sus mitos. Según lo anterior, los mexicas pasaron por un proceso de dominio y sometimiento por parte de los aztecas. Así decidieron emigrar en la búsqueda de un nuevo territorio con un futuro glorioso y lleno de riquezas. Este grupo fue guiado por su sacerdote Mexi o Huitzilopochtli, el dios que protegía a los Mexitin o mexicas, como se denominaron.

Después de un recorrido entre varias regiones, llegaron a Texcoco, su hogar definitivo, en 1325. El asentamiento en la región tuvo características positivas como abundante flora y fauna, un ventaja para la defensa por el simple hecho de ser un islotey dificultar la entrada y salida. No obstante, también tuvo características negativas como la existencia de poca agua potable, además que el terreo del islote carecía de piedras y 
madera. Por otro lado, entre las condiciones políticas, hubo varios enfrentamientos entre las poblaciones cercanas a la región, así como también existieron alianzas entre las ciudades más importantes como Azcapotzalco, Coatlinchan, Xochimilco y Culhuacán.

\section{Estructuración Estado hegemónico.}

El poder de la región recaía en tres ciudades del islote: Texcoco, Tlacopan y Tenochtitlán, estas ciudades se hicieron Ilamar la Triple alianza. Entre sus tareas resolvían enfrentamientos entre las entidades políticas, vigilaban la seguridad de la región, fomentaban la ayuda entre las ciudades aliadas. Entre ellas estaba centralizado el poder; además de la reorganización de la administración pública, así como el control y la difusión de la ideología militar.

México-Tenochtititlán fue gobernada por tlatoani, los primeros tres hermanos Axayacatl, Tizoc; el tercero alcanzó el poder impulsando el comercio a grades distancias. Moctezuma Xocoyotzin fue el tlatoani que logró dirigir la ciudad al pleno desarrollo; durante su estadía en el poder, la población creció de 150,000 a 300,000 habitantes.

Posteriormente continuaron dos gobernantes, a saber, Cuhitlahuac y Cuahtémoc quienes resistieron al dominio español. Cuando los mexicas empezaron su expansión hacia otros territorios fueron dominados, sin embargo, obtuvieron apoyo de otros pueblos y hubo contiendas para resistir su dominio.

\section{Interpretación de la obra La Fusión de dos Culturas}

La obra exalta los valores de las culturas mesoamericanas, específicamente la de la cultura mexica. Algunos de estos valores son la grandeza y la fuerza; pueden visualizarse en la obra a través de las figuras del guerrero águila y el conquistador español, en las insignias de los dos bandos: los penachos y estandartes indígenas y las banderas españolas. El pintor da una breve alusión de la conquista que representa la guerra de Conquista contra México y muestra símbolos que evocan lo mexicano. Por ejemplo, el caso del guerrero águila perteneciente a la cultura náhuatl que floreció en Mesoamérica.

En lo particular, en el espacio pictórico, el artista resalta la escena con colores llamativos e intensos utilizados en algunas culturas mesoamericanas, en especial el rojo teotihuacano; se obtenía a través de la combinación de diversos pigmentos a base de minerales de la región (por ejemplo el hematita y el azul maya). Este color básicamente es de origen mineral, donde se implementaba la práctica de una técnica similar a Teotihuacán (Magaloni, 1993). 
En la escena, lo primero a resaltar está en el fondo; se percibe el enfrentamiento que tuvo el pueblo mexica en contra de los españoles. El ambiente se muestra con intensidad y con elementos representativos de ambas culturas, como las lanzas de los mexicas y las espadas clavadas de los españoles.

Por último, los rasgos faciales de los personajes, centro de la obra; muestran características de algunos pobladores mesoamericanos, como es el caso de la cultura olmeca. El guerrero águila muestra ojos rasgados que el artista compara con dos (2) grandes nueces y el color de piel morena.

\section{Análisis del atavío y el armamento del guerrero mexica y caballero español}

\section{Guerrero mexica.}

Para el análisis del atavío y del armamento del guerrero mexica presentes en el mural, es importante explicar al lector la función de un arma en el campo de batalla. Un arma tiene dos (2) funciones en particular: ofender y defender para que los guerreros desarrollaran tácticas en combate, conocido como "sistema de armamento" (Cervera, 2005, p. 68). En estecaso es de suma importancia señalar que la escena de la obra"La Fusión de dos Culturas" se lleva en un ambiente de guerra de conquista, para la obtención diversos recursos, tributos, tierras y mano de obra dirigidos a la infraestructura de la ciudad, así como también a legitimar su podery expansión política(Cervera, 2005, p. 68).

Sobre el armamento del guerrero mexica, y lo descrito por el artículo del Dr. Marco Cervera en la Revista Arqueología Mexicana, hay armas que se utilizaban en el periodo Posclásico Tardío pero el pintor González Camarena no ilustró en su mural. Por ejemplo:

1. Átlatl o la honda: arma de contacto cuerpo a cuerpo.

2. Macuáhuitl: bastón de madera de aproximadamente $70 \mathrm{~cm}$ de largo; en el cuerpo de esta arma estaba incrustadas navajas de obsidiana (Cervera, 2005, p. 69).

Dentro de la escena tampoco se visualiza armamento alguno para el combate a larga distancia como Átlatl (del cualya se ha hecho su descripción), tlahuitolli o arco, flechas o mitl, micómitl o caja para guardar las flechas, temálatl o hondas, átlatl o lanzadores y cerbatanas. Lo que corresponde al armamento cuerpo a cuerpo, o armas ofensivas 
a corta distancia, no se perciben mazos quauhololli (podía causar graves fracturas en la cabeza) o cuchillos o técpatl. En la obra el guerreo mexica solo sostiene una laza o teputzopilli que clava al soldado español. Además, en la parte central de estos dos (2) personajes sobresale una mano que realiza la misma acción del guerrero mexica (Cervera, 2005, p. 71). Lo descrito anteriormente es ejemplifico a detalle en la Figura 2.

Figura 2. Ilustración del armamento mexica.

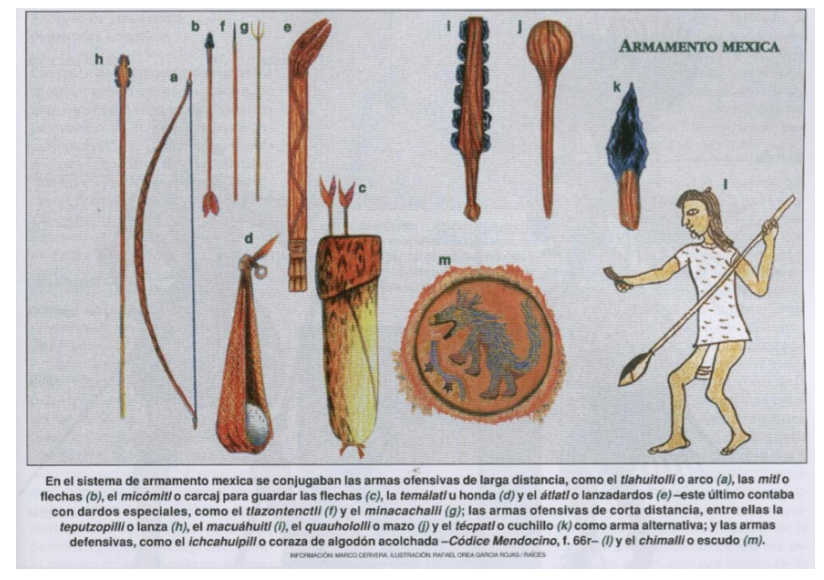

Fuente: García, R. (2005), Recuperado de Revista Arqueología Mexicana Vol. XII Núm. 70, p. 70.

Una vez contrastada la información proporcionada, Ibarra (2015) menciona que las armas ofensivas más comunes entre los mexicas eran arcos, flechas, hondas, porras, lanzas, picas, espadas y dardos. Referente a la protección del guerrero mexica, no hay muestra de escudo alguno de madera, ni corazas de algodón (endurecidas con sal)en la pintura. Lo que si puede percibirse es elyelso portado por el guerrero, semejante a un águila. Cervera menciona que el yelmo, utilizado como casco, además de servir para su protección, asustaba a sus enemigos; el águila, animal símbolo del orden militar al cual pertenecían (Cervera, 2005).

En contraste con la información anterior, Ibarra (2015) nombra las armas ofensivas más comunes entre los mexicas, a saber, los arcos y flechas, hondas, porras, lanzas, picas, espadas, dardos. Ahora bien, en lo relacionado con la protección del guerrero mexica, no hay muestra de algún escudo de madera, ni corazas de algodón -eran endurecidas con sal- en la pintura. Lo que si puede percibirse es el yelso portado por el guerrero, semejante a un águila. Cervera menciona que el yelmo, utilizado como casco, además de servir para su protección, asustaba a sus enemigos; el águila, animal símbolo del orden militar al cual pertenecían (Cervera, 2005). 
De acuerdo con el análisis del atavío del guerrero mexica, se percibe que viste un uniforme que simboliza una águila, dentro de este usa corazas de algodón. Ibarra (2015) menciona cómo el guerrero mexica de la escena pictórica de Camarena no pertenece a un guerrero de alta jerarquía (distinguía agrado militar y sus funciones); su vestimenta no presenta coseletes, chaleco o abrigo de algodón adornado con plumas, oro y plata; portaban también alhajas en cuello, orejas, labios, y adornaban la cabeza con alhajas y penachos de plumas. En el fondo de mural del lado derecho de la escena se observan una serie de banderas; servían a los guerreros para identificarse en el campo de batalla.

Por su parte, Macías (2015) hace referencia a la indumentaria de combate; además, dentro del mural no existe la presencia de escudos o chimalli hechos de madera, cuero, cobre, caparazón de tortuga o fibras vegetales entretejidas, recubiertas de algodón. Tampoco tenían una variedad de diseños (redondos, cuadrados y rectangulares) o representaciones iconográficas relacionadas al estatus, merito o fuerza. La decoración era con plumas o incrustaciones de piedra y metal.

El guerrero águila en el mural está ataviado con una armadura o Ichcahuipilli o escaupil,(traje de cuerpo completo hecho de algodón), se maceraba en sal ordinaria para hacerlo duro y más resistente Lo que puede afirmarse es que guerrero mexica cuenta con un casco que imitaban ser las cabezas de animales sagrados en este caso un águila (también como jaguares, águilas o garzas); estaban hechos de madera, acolchadas o hueso, y solían estar decorados con plumas o labrados (Macías, 2015).

Uno de los elementos que se utilizaban en batalla y que aparecen en el mural de Camarena son los estandartes: "representaban las insignias del estado hechas de oro, plumas o de otro material, además cada grupo de 200 o 300 guerreros tenía su estandarte particular, que se distinguía de los demás por su forma y color" (Ibarra, 2015, p. 151).

A continuación se describe las armas presentes por hallazgos arqueológicos en la Conquista, sin embargo, a la hora de evidenciarlo en la obra de Camarena están ausentes. Por lo que se afirma que la representación pictórica del artista es una mera recreación simbólica a causa de su propio bagaje cultural, tal vez construido en gran parte por fuentes históricas que abordan en los libros este tipo de sucesos, sin tomar en cuenta distintos enfoques como la arqueología.

Una tercera opinión referente al uso de las armas de los mexicas es realizada por Macías (2015); menciona que las flechas (o yaomitl) y los arcos (o tlahuitolliestaban) en madera estuvieron presentes en las batallas de conquista y postconquista; la mayoría de las flechas contaban con plumas pegadas con resina en la parte posterior. De la 
honda se lanzaban piedras como esferas de arcilla, lanzas o tepoztopilli; servían para ser arrojadas y/o estocar; las puntas podían ser de piedra, metal o madera endurecida, jabalina y venablo o tlacocochtli y mitl. Además, eran varas de madera con puntas de obsidiana o espina de pez, los dardos hechos de roble, con variedad de formas y tamaños; se les aplicaba ponzoña en las puntas para hacerlos más dañinos; el veneno era a base de sustancias tóxicas de animales cadavéricos, jugos vegetales y gérmenes.

Entre las armas de impacto se encuentra el mazo o huitzauhqui, hecho de madera con hojas de obsidiana (rectangulares, ovales o puntiagudas) pegadas en cada uno de los lados (Macías, 2015). La única arma percibida en el mural de Camarena es la lanza o tepoztopilli, sostenida por el guerrero águila y clavada sobre la armadura del caballero español. Sobre esto, Cervera (2017) refiere que la lanza fue una de las armas predilectas en el arsenal mexica, tal como lo atestiguan las diferentes representaciones en el arte escultórico mexica, así como en muchos de los códices. Por ejemplo, este tipo de lanza aparece constantemente registrado en el "Lienzo de Tlaxcala"; hace referencia a las batallas libradas por los indígenas contra los españoles.

\section{Caballero español.}

Una vez revisada la imagen a detalle, no se encuentran armas de fuego por parte del caballero español; la escena se centra en un enfrentamiento cuerpo a cuerpo, donde los cuerpos de cada personaje se convierten en extensiones de sus propias armas de combate. A continuación, retomo con mayor detenimiento las armas utilizadas, en relación con los hallazgos arqueológicos en la Conquista.

En lo correspondiente al armamento europeo, Cervera (2005) distingue dos (2) tipos de armas: de metal y de fuego. El primero contempla un proceso de origen desde la época medieval y renacentista. En las armas ofensivas o de metal se encuentran principalmente espadas como la cruciforme, espadas de metro y medio (llamadas mandobles). Entre las armas a larga distancia utilizadas en contra de la caballería, se encontraban una especie de lanzas con una cuchilla al frente (llamadas alabardas), así como también ballestas, pistolas y rcabuces.

Encomparacióncon lo descrito en el artículo de la RevistaArqueología Mexicana, antes mencionado, y lo percibido en los elementos visuales en el mural de Camarena, existe poca similitud en la armadura y el armamento del caballero español. Por ejemplo, entre las similitudes se encuentra ataviado con peto, cubrebrazos, manoplay grebas. Por otra parte las diferencias que presentan por la posición de caballero no puede observase si cuenta gola en el cuello y escarcela; el casco no es mirrón de cresta (Cervera, 2005). 
Con respecto a la vestimenta defensiva del caballero español, Macías (2015) menciona que el coselete se usaba para cubrir el tronco y protegerlo contra el impacto de los proyectiles o armas de impacto. Esta armadura estaba formada de peto (protege la parte superior de los muslos) y guarniciones de brazos y manos articuladas; los cascos o celadas prevenían los ataques en la cabeza y estaban cubiertos de algodón o lana en el interior. Además, la cota de malla fue muy utilizada por los españoles y los escudos eran de metal o cuero, de superficie convexa.

Por otra parte, del armamento, la espada que se muestra es diferente en la hoja y el pomo; tampoco cuenta con izquierdilla y mucho menos presenta alabarda. Un tercer punto de vista es referente al armamento del ejército español; Macías (2015) menciona que el armamento europeo se divide en arrojadizas y/o de lanzamiento; de impacto, y de fuego.

A propósito del fondo del mural plasmado por una gama de tonalidades naranjas, amarillas y rojas, permiten generar un ambiente de caos por los personajes enfrentándose. Así, a continuación se aborda información detalla de cada una de estas armas, en relación con los hallazgos arqueológicos en la Conquista. Para el ataque a distancia eran utilizadas ballestas; comúnmente utilizadas por su efectividad, fuerza y puntería. La técnica para su uso consistía en un grupo de ballesteros divididos en dos (2): mientras unos cargaban, otros tiraban (Macías, 2015).

Ahora bien, dentro de las armas de impacto para el combate cuerpo a cuerpo, se encuentra la espada; utilizadas por los infantes, quienes tenían dominio en el manejo de este instrumento. Otras armas de impacto para el combate cuerpo a cuerpo son las alabardas utilizadas para desequilibrar, picar o cortar al enemigo; las polihachas, usadas por el ejército de a pie, causaban gran daño como amputaciones de extremidades o heridas graves (Macías, 2015).

Una vez expuesta la información del armamento utilizado en la conquista del Nuevo Mundo, se puede observar que ninguna de las armas antes descritas están presentes en el mural de Camarena, sólo una espada que no concuerda con las descripciones y especificaciones del arma de impacto. Sin embrago, dentro de la atmosfera del mural, y por la diversas tonalidades entre el naranja, amarillo y rojo utilizado por el artista simbólicamente, es evidente la presencia del fuego. Patrick Johansson (2019) menciona que: "en la cultura náhuatl prehispánica, el fuego determina, en última instancia, la generación y regeneración de los seres y de las cosas. [...] El fuego, la integración de los opuestos" (pp. 78-83). 
Porende, es preciso inferirqueel pintor basó su interpretación en fuentes históricas, en su mayoría libros que abordaron acontecimientos memorables de las descripciones de rituales, estratificación social, asentamiento de los mexicas, invasión europea, por mencionar algunos sucesos. Sin embargo, deja de lado los hallazgos arqueológicos referentesalasarmasencontradasenel campo debatalla.Además, constatasucomparación entre lo que se hace mención en los textos históricos y lo que se percibe en los códices.

Por último, un punto importante por resaltar; dentro de mural puede percibirse un recurso utilizado por el caballero español para combatir sus batallas en el Nuevo Mundo: animales como caballos y perros. Macías (2015) hace referencia a los caballos y su uso como medio de transporte, para trasladarse por caminos largos y dificultosos; atravesar ríos, cargar alimentos, armas y movilizar heridos.

Los perros no son un elemento pictórico ilustrado en el mural. No obstante, Macías (2015) los contempla en su investigación; al respecto menciona: "la implementación de los perros fue vista como un acto de crueldad, estos animales despedazaban alrededor de cien indios en el transcurso de una hora, como resultando era una muerte brutal y sangrienta" (p. 193).

\section{Conclusión}

Lo anterior presenta y aborda la información referente a la vida del autor, sobre el contexto histórico de la cultura mexica, para el entendimiento más a profundidad sobre la temática y los valores que el pintor quiso exaltar y plasmar en su mural. Esta primera parte evidencia a Camarena en la realización de su obra artística; sólo visualizó y se dio a la tarea de investigar, consultar y apegarse a las fuentes históricas como textos que narran acontecimientos para la enseñanza en los niveles educativos, como parte de una enseñanza nacionalista. Así, la obra deja de lado la verdadera visión del combate en batalla, la escena a la cual nos remite su mural; el entrenamiento entre un guerrero águila y un caballero español, suceso que denota la batalla en la toma de Tenochtitlan.

Por otra parte, se perciben grandes diferencias como resultado del atavió y del armamento de cada uno de los personajes presentes en este espacio pictórico. Entre ellas se ubica al guerrero mexica, en especial, el calzado lo cual no puede ser; esta cultura es presentada con huaraches, según los hallazgos arqueológicos y los códices.

La descripción realizada en el presente trabajo es referida por la investigación de los especialistas en el tema como el Dr. Marco A. Cervera Obregón, el Lic. Miguel Ángel Ibarra Bucio y la Maestra Adriana Macías Madero. Según lo anterior, sólo se presenta una lanza, perteneciente a las armas para combate a larga distancia. Entonces, no hay presencia de alguna otra arma, según el listado antes mencionado y clasificado en el mural. 
Entre las similitudes se encuentra la indumentaria para la batalla; el guerrero mexica vestido con un uniforme y un yelmo que asemejan a una águila, uno de los elementos pictóricos que forman parte de fondo de la escena del mural. Además, es evidente la serie de estándares que servían a los guerreros para identificarse en el campo de batalla.

Con respecto a la imagen presentada al caballero español, también se muestran una diferencia; en la mayoría de los textos consultados para la educación básica de nuestro país, siempre se ha presentado al caballero español ataviado de pies a cabeza con una armadura y una espada como arma de combate. Sin embargo, esta espada en realidad corresponde al contexto en que se llevó la toma de Tenochtitlan. A continuación, se eliminarán estos mitos presentados en estas fuentes.

A grandes rasgos, y tomando en cuenta las investigaciones presentadas por los especialistas antes mencionados, el mural de Camarena efectivamente muestra un guerrero español vestido con una armadura entre sus elementos que lo conforman. Viste un peto para proteger la parte superior de los muslos; una manopla o manos articuladas, cubrebrazos o guarniciones de brazos; casco (no es mirrón de cresta) o celada que prevenían los ataques en la cabeza. Además, no es posible observar si cuenta gola en el cuello y espada, así como si muestra diferencias en la hoja y el pomo.

Para finalizar, el presente artículo expone la importancia del análisis sobre una obra artística con esa clase de temática. Es necesario tomar en cuenta los hallazgos arqueológicos y los códices para acercarse con mayor precisión a la imagen verdadera del guerreo; con la indumentaria en sus rituales y en el campo de batalla.

\section{Referencias}

Cervera, M. (2005). El Sistema de Armamento entre Los Mexicas. Revista Arqueología Mexicana, $12(70)$.

Cervera, M. (2007). El armamento entre los mexicas. Madrid: Instituto Histórico Hoffmeyer.

CONACULTA. (1996). Jorge González Camarena: Antología. México: CONACULTA-INBA.

Ibarra, M. (2015). Aplicación del arte de la guerra en el México Prehispánico. Congreso Nacional de Historia Militar a través de los Archivos Históricos. México: Secretaría de la Defensa Nacional y Dirección General de Archivo e Historia. 
Johansson, P. (2019). El agua y el fuego en el mundo náhuatl prehispánico. Revista Arqueología Mexicana, 88.

López, A. \& López, L. (2001). El pasado indígena. México: Fondo de Cultura Económica.

Luna, A. (1981). Jorge González Camarena en la plástica mexicana. México: UNAM.

Macías, A. (2015). Las batallas post conquista: visión histórica de sus estrategias militares. Congreso Nacional de Historia Militar a través de los Archivos Históricos. México: Secretaría de la Defensa Nacional y Dirección General de Archivo e Historia.

Magaloni, D. (1993). Técnicas de la pintura mural en Mesoamérica. Revista Arqueología Mexicana, 16. 